\title{
Relevance and L2 Learners' Interpretation of Reflexive Anaphora in VP-Ellipsis: An Exploration of the Relationship between Relevance Theory and Typological Universals
}

Hongguang Ying

University of Colorado

\begin{abstract}
Twenty-eight intermediate and twenty-two advanced L2 learners (the experimental groups) and twenty native speakers of English (the control group) participated in a study that investigated second language learners' interpretation of reflexives in the VP-elliptical sentences. 17 experimental sentences in a null context, 17 experimental sentences followed by a referential context favoring the "strict" reading interpretation, 17 experimental sentences followed by a non-referential context not favoring the "strict" reading interpretation, and 51 filler items were presented to the participants using a judgment task in which each sentence is followed by two alternative interpretations (Frazier \& Cliffton, 2000). The results indicate that adult L2 learners' interpretation of such construction in English was constrained by the minimal processing cost and contextual effects of RT. They interpreted the
\end{abstract}


reflexive in a null context "sloppily", indicating the constraints of the minimal processing cost of RT. The contextual effects of RT were shown in their "strict" reading of the reflexive in a referential context. The relationship of relevance theory and typological universals in terms of context, constraints, economy and cognitive considerations is also discussed.

Keywords: Relevance Theory, reflexive anaphora, VP-ellipsis, typological universals

\section{Introduction}

The publication in 1986 of Relevance: Communication and Cognition by Dan Sperber \& Dreidre Wilson set in motion a wideranging program of research into human communication (For a recent overview, see Ramos 1998). But actual relevance-theoretic research in applied linguistics has barely begun (Foster-Cohen 2000). Although fairly well studied in generative grammar (e.g., Fiengo \& May 1994, Johnson 2001, Safir 2004), reflexive anaphora in VPellipsis ((1) below) has not been studied in applied linguistics research.

(1) John defended himself and Bill did too.

Further, no recent second language studies on reflexive binding have examined this syntactic structure from the perspective of Relevance Theory (RT), a pragmatic theory developed by Sperber \& Wilson (1986/1995). This study intends to bridge the gap.

Reflexive anaphora in VP-ellipsis is interesting in that it allows two possibilities of interpretation (Fiengo \& May 1994):

(2) a. $\mathrm{John}_{\mathrm{i}}$ defended himself $\mathrm{i}_{\mathrm{i}}$ and Bill $\mathrm{j}_{\mathrm{j}}$ did [defend himself $\mathrm{j}_{\mathrm{j}}$ too. (i.e., Bill) 
b. John $n_{\mathrm{i}}$ defended himself $f_{\mathrm{i}}$ and Bill $\mathrm{j}_{\mathrm{j}}$ did [defend him ${ }_{\mathrm{i}}$ ] too. (i.e., John)

In (2a) the reflexive himself in the elided VP co-refers with Bill. This interpretation, known as the sloppy reading, is set by the requirement of Principle A of Binding Theory. In (2b), the pronoun him in the elided VP co-refers with John - the subject of the higher clause. This interpretation, known as the strict reading, is set by Principle B of Binding Theory.

\section{Previous Analyses: Semantic versus Syntactic}

It is relatively uncontroversial that reflexives have a sloppy reading, on the assumption that they function obligatorily as bound variables. But there has been disagreement in the linguistic literature on the status of a strict reading. Work by Dalrymple, Shieber, and Pereira (Dalrymple, Shieber \& Pereira 1991, Shieber, Pereira \& Dalrumple 1996) represents the semantic approach. Dalrymple, Shieber \& Pereira (1991) proposed that the availability of a strict reading of a reflexive depends on the semantic property of individual verbs. They distinguished between verbs such as lock and defend, stating that no matter what the structure is, the verb defend allows a strict reading, but not the verb lock.

(3) Bill defended himself against the accusation, and John did, too.

(4) John locked himself in the bathroom when bad news arrived, but Bill would never do so.

She explained that defend gets both sloppy and strict readings because it does not intrinsically impose a requirement of coreference 
162 Relevance and L2 Learners' Interpretation of Reflexive Anaphora in

between its subject and object. On the other hand, lock does not allow a strict reading because it imposes a requirement of coreference between its subject and object. But, as Hestvik (1995) pointed out, the semantic properties of lexical items do not determine whether reflexives allow a strict reading. Compare (4) with (5):

(5) John locked himself in the bathroom before Bill could.

Evidently a strict reading is possible in (5), suggesting that an account based on the semantic property of verbs does not work (Hestvik 1995).

Kitagawa (1991) approached the problem of strict reflexives by reconstructing reflexives as pronouns at LF. She suggested that a feature [+anaphor] on the reflexive can be suppressed in the copying of the antecedent VP into the elided VP. This is illustrated in (6), where LF of (6a) is (6b) with the reflexive reconstructed as the pronoun:

(6) a. John likes himself $_{\mathrm{i}}$, and Bill does too.

b. John likes $_{[+\mathrm{a}]}$ himself $_{\mathrm{i}}$, and Bill likes $[-\mathrm{a}] \operatorname{him}_{\mathrm{i}}$ too.

Fiengo \& May (1994) developed Kitagawa's suggestion and proposed a structural account under the term "vehicle change". They state that though at the level of LF, the empty VP is replaced with material as a function of a dependency on the VP in the preceding clause, the strict reading of reflexives involves a change to the pronoun from the reflexive. It comes about as follows: A reflexive, when copied from the first to the second clause, is allowed to change to a pronoun. Thus, vehicle change allows the strict reading by reconstructing the reflexive as a pronoun, which, as set by Principle B of Binding Theory, cannot be locally bound. This explains why the reflexive in the overt VP (6a) can be reconstructed 
as the pronoun in the elided VP (6b), referring back to the nonlocal subject NP John.

To sum up, Dalrymple et al. (1991) proposed that the strict reading of reflexives derive from the semantic property of individual verbs, but their semantic account was deemed unsatisfactory. The property of verbs does not determine the strict reading of reflexives in VP-ellipsis (Hestvik 1995). In contrast, Fiengo \& May (1994), based on Kitagawa (1991), proposed a structural account under the name of "vehicle change." The structural account says that the strict reading of reflexives derive from "vehicle change," which allows reflexives in the elided VP to be interpreted as pronouns at $\mathrm{LF}^{1}$.

Neither account addresses how readers would interpret reflexives in VP-ellipsis. In other words, neither account tells us how readers would interpret this strict-sloppy ambiguity.

\section{Prior L2 Research in Reflexive Binding}

Previous L2 research in reflexive binding studied linguistic constraints such as Binding Theory (Chomsky 1981, 1986), the movement at LF approach (Cole \& Sung 1994), the relativized SUBJECT approach (Progovac 1992, 1993), constraints that operate at LF (Chomsky 1993, 1995) and the Internal Subject Hypothesis (Koopman \& Sportiche 1991). Recent L2 studies on reflexive binding examined L2 learners' interpretation of a cluster of properties of UG such as a link between monomorphemic reflexives and long-distance subject orientation.

Thomas (1995) investigated whether L2 learners of Japanese know that morphologically simplex anaphor zibun has the property

\footnotetext{
Following Kirakawa (1991), Fiengo and May (1994) \& Hesvik (1995), we assume that the reflexive in the VP-elliptical structure can be interpreted sloppily as a bound anaphora or strictly as a pronoun.
} 
164 Relevance and L2 Learners' Interpretation of Reflexive Anaphora in

of subject orientation. Her experiments included 58 learners of Japanese as a foreign language, 34 in a low proficiency group and 24 in a high proficiency group. Subjects were tested with a truthvalue judgment task involving stories and pictures. The results showed that most of her subjects at a high-proficiency level who bind zibun long distance reject object antecedents, an empirical finding consistent with the predications of the movement at LF approach. But the lower-proficiency learners failed to bind reflexives long distance. Thus, the issue of subject-orientation could not be investigated for these learners, and these data are less readily accounted for from the perspective of movement at LF.

Yip \& Tang (1998) investigated the interpretation of English reflexives by Cantonese-speaking learners of English. They employed a sentence judgment task to probe the learners' knowledge of binding. They found that learners initially identified English reflexives with the monomorphemic reflexives in their native language, and that as learners became more advanced, they were able to treat the binding properties of the L2 as an independent system consistent with Universal Grammar.

Bennett \& Progovac (1998) expanded on Bennett's (1994) investigation of the interpretation of English reflexives by SerboCroatian learners of English. They used a picture-identification task and a multiple-choice questionnaire to investigate whether SerboCroatian speakers learning L2 English apply the +AGR parameter setting and initially transfer the $\mathrm{L} 1 \mathrm{X}^{\mathrm{O}}$ reflexive anaphor type to the interlanguage grammar and whether Serbo-Croatian speakers learning L2 English who retain the +AGR/ $\mathrm{X}^{\mathrm{O}}$ reflexive configuration will be able to compute new binding domains in the interlanguage grammar. The study yielded evidence of transfer of the L1 $\mathrm{X}^{\mathrm{O}}$ anaphor setting to their interlanguage grammar. They treated English XP reflexives on a par with $\mathrm{X}^{\mathrm{O}}$ reflexives in their native language in sentences lacking an AGR in the local domain, namely, sentences with reflexives in complex noun phrases. But the 
study also showed the evidence that reflexive binding in an L2 is constrained by UG. When a binding domain resulting from the interaction of an $\mathrm{X}^{\mathrm{O}}$ reflexive and an AGR parameter setting is not instantiated in the L1, L2 learners set the domain in the light of UG constraints.

MacLaughlin (1998) conducted experiments on the acquisition of English reflexives by native speakers of Chinese and Japanese. She used a sentence judgment task to investigate UG constraints and L1 induced language mapping. Her results indicate that although transfer is an important factor in L2 development, L2 learners advance beyond the constraints imposed by their native languages. That is, L2 learners can acquire a system of reflexive binding that is not found in the native language (nor in the target language), but one that is nevertheless constrained by Universal Grammar.

Not until recently did L2 researchers pay attention to reconstruction, a syntactic phenomenon that has attracted a great deal of attention in current linguistic research (e.g., Barss 1986, 1988, 1993, 1994, 2001; Chomsky 1993, 1995; Cinque 1982; Culicover 1997; Haegeman 1994; Heycock 1995; Huang 1993; Lasnik 1999, 2001; Reuland \& Everaert 2001; Roberts 1997; Takano 1995). Reconstruction refers to sentences with a reflexive inside a moved NP (7) or sentences with a reflexive inside a moved predicate (8).

(7) $\mathrm{John}_{\mathrm{i}}$ wonders which pictures of himself $\mathrm{i}_{\mathrm{j} / \mathrm{j}}$ Bill $_{\mathrm{j}}$ likes.

(8) How proud of herself $*_{i j}$ does Mary $y_{i}$ think that Nancy $y_{j}$ is?

It is relevant to two options at $\mathrm{LF}^{2}$ (Chomsky 1993) in that the

2 In accounting for ambiguity of antecedence of a reflexive inside a moved NP, Chomsky (1993) proposes two options. One option assumes that at LF only whmaterial is in wh-positions. In other words, only which adjoins to $w h$. As a consequence, non-wh-material that is overtly moved along with a $w h$-element is 
reflexive inside a moved NP can be bound by either the lower or higher subject. It is also relevant to the syntactic constraint of the Internal Subject Hypothesis ${ }^{3}$ in that the reflexive inside a moved predicate can only be bound by the lower subject.

Ying (1999) used a sentence judgment task to investigate how English-speaking learners of Chinese interpret reconstruction in Chinese, namely, sentences with ziji 'self' inside a moved noun phrase (NP) or predicate. The results indicate that English-speaking learners of Chinese resorted to options of UG (the morphological constraint of monomorphemic reflexives and the syntactic constraint of the Internal Subject Hypothesis) when they interpreted reconstruction

placed back into its original position and only wh-elements undergo covert movement to $w h$-positions at LF. This yields (1a), which is interpreted in (1b):

(1a) John wondered [wh which ${ }_{i}$ Bill saw [wh $t_{i}$ pictures of himself].

(1b) John wondered [which $\mathrm{x}$ [Bill saw [x picture of himself]].

Under this option, himself takes Bill as antecedent by Principle A at LF.

The other option assumes that which pictures of himself adjoins to wh (2a below). Then complementary portions are deleted from the fronted phrase and its copy. Namely, wh is deleted from the fronted phrase, whereas the phrase adjoined to $w h$ is deleted from the copy. This yields $(2 b)$, and it is interpreted in $(2 \mathrm{c})$ :

(2a) John wondered [wh which picture of himself] Bill saw [wh which picture of himself]]. Copy

(2b) John wondered [which pictures of himself] $]_{i}$ Bill saw [wh $\left.t_{i}\right]$ ].

(2c) John wondered [which $\mathrm{x}$, $\mathrm{x}$ a picture of himself] [Bill saw $\mathrm{x}$ ].

Under the second option, himself takes John as antecedent by Principle A at LF. The available two options at LF explain why himself can seek either John or Bill as its antecedent.

3 The Internal Subject Hypothesis (e.g., Koopman and Sportiche, 1991) says that each sentence contains a trace of the subject in the VP position, and that when a VP is fronted, the trace of the subject is fronted as well. It follows that the reflexive inside a moved predicate can only be bound by the local antecedent, since the fronted predicate carries the trace of the local subject. 
in Chinese. But the study also presented evidence of L1 induced language mapping for non-movement sentences (e.g., John ${ }_{i}$ said that Bill $_{\mathrm{j}}$ likes pictures of himself $*_{*_{\mathrm{i}} \mathrm{j}}$ ). The English-speaking learners of Chinese identified the wider parameter setting of ziji in Chinese with the narrower setting of reflexives in English.

Ying $(2000,2003)$ used a timed judgment task to study how Chinese-speaking learners of English interpret reconstruction in English. The results suggest that the Internal Subject Hypothesis (ISH) constrained their interpretation of reflexives inside a moved predicate. The Chinese L2 learners bound the reflexive in predicate fronted sentences locally. However, the experiment also presented evidence of mapping-induced L1 effects for non-movement sentences. The Chinese-speaking learners of English mapped the long-distance property of ziji onto English reflexives while interpreting such sentences.

To the best of my knowledge, none of published studies on reflexive binding in second language research has examined reflexive anaphora in VP-ellipsis. Nor am I aware of any L2 studies that examine this linguistic phenomenon from the perspective of Relevance Theory, a pragmatic theory that is gaining increasing attention in L2 acquisition studies (Cameron \& Williams 1997; Carroll 2001; Pennington 2002; Ying 1996, 2004). This study provides a relevance-theoretic account of L2 learners' interpretation of reflexive anaphora in VP-ellipsis.

\section{Relevance Theory}

Relevance Theory (Sperber \& Wilson 1986/1995), a cognitive theory of communication, proposes that human cognition is relevance-based: we pay attention to information that appears relevant to us, construct relevant representations of such information, and process these representations in a context that maximize its 
relevance. It takes Grice (1975) as a point of departure, but uses the principle of relevance to subsume Grice's Cooperative Principle and four conversational maxims. Sperber \& Wilson (1986:125) define relevance in terms of two conditions:

Extent condition 1: an assumption is relevant in a context to the extent that its contextual effects in this context are large.

Extent condition 2: an assumption is relevant in a context to the extent that the effort required to process in this context is small.

'Relevance' thus encompasses two factors: contextual effects and processing effort. On the contextual-effect side, the speaker guarantees both that the proposition conveyed will be optimally relevant to the hearer and that this relevant information will yield adequate contextual effects to justify the hearer's attention. Contextual effects are achieved when newly presented information interacts with the context of existing assumptions in one of three ways: by strengthening an existing assumption, by contradicting an existing assumption, or by combining with an existing assumption to yield a contextual implication, a logical implication derivable neither from the new information alone, nor from the context alone, but from the new information and the context combined. Newly presented information is relevant when it achieves contextual effects in a specific discourse. On the processing-effort side, the speaker who wants to achieve adequate contextual effects makes sure that the utterance requires no more than the hearer's minimum justifiable processing effort. In other words, the hearer will bear no unjustifiable cost in processing the speaker's utterances, for 'any increase in unjustifiable processing effort of the hearer is an increase in risk of misunderstanding' and 'any increase in processing effort detracts from overall relevance and might cause the overall relevance of the utterance to fall below an acceptable level' (Wilson \& Sperber 1991:588). It follows that the right interpretation is the 
one that yields an overall interpretation that is consistent with RT.

RT rejects traditional views of communication as a straightforward decoding of information. To Sperber \& Wilson, communication has to do with the addressee's inference of the communicator's intentions. They view inferential comprehension as involving the construction and manipulation of conceptual representations, and linguistic encoding as a particular form of inferential processing. Thus, linguistic constructions may be expected to encode two basic types of information: concepts or conceptual representations on the one hand, and procedures for manipulating on the other (Wilson \& Sperber 1993). Conceptual information gives rise to representations that provide input to inferential processes of linguistic interpretation, while procedural information provides constraints on the inferential computations performed over these conceptual representations (Nicolle 1998).

Within RT, the idea that a linguistic expression may impose procedural constraints on the inferential phase of comprehension was put forward by Blakemore (1987, 1988, 1992, 1997, 2000, 2002). She characterized discourse connectives such as 'so' and 'after all' as constraining the inferential processing of propositions, namely, constraining the inferred conclusions from linguistic expressions containing the connectives.

(9) He is an Englishman, so he is brave.

(10) He is brave; he is, after all, an Englishman.

'So' signals an inferential connection between the two propositions in (9) in much the same way as 'after all' signals an inferential connection between the two propositions in (10). Whereas 'so' introduces a proposition which is understood to be proven or justified by the preceding one, 'after all' introduces a proposition which is understood as proof of the preceding one. As 
Blakemore (2002) pointed out, such expressions contribute to relevance by guiding the hearer towards the intended contextual effects, hence reducing the overall computational effort required.

To extend Blakemore's analysis of linguistic expressions, we would like to find out whether ensuing referential sentences impose procedural constraints on inferential processing, that is, whether there is an inferential connection between the information encoded by ensuing referential sentences and the information encoded by experimental sentences.

\section{Research Questions}

Given the basic premises of RT outlined in Section IV, we are interested in finding out whether the principle of relevance constrains second language learners' sentence comprehension. To be more specific, we are interested in finding out whether the minimal processing effort and the contextual effects of RT constrain adult L2 learners' processing of syntactically ambiguous sentences and whether an ensuing referential sentence places procedural constraints on the inferential phrase of comprehension on the part of L2 learners. Thus, we set out the following research questions for investigation.

(a) Do L2 learners follow the constraint of the minimal effort of $\mathrm{RT}$ in processing reflexive anaphora in VP-ellipsis?

(b) Does an ensuing referential sentence impose procedural constraints on the inferential phase of comprehension by L2 learners when they process reflexive anaphora in VP-ellipsis, thus showing the contextual effects of RT? 


\section{The Present Study}

\subsection{Subjects}

The subjects were 28 immediate and 22 advanced Chinesespeaking learners of English (the experimental groups) and 20 native speakers of American English (the control group). The intermediate learners were second-year university students enrolled in intermediate English-learning classes. The advanced learners were fourth-year university students enrolled in advanced English composition classes. The fifty Chinese-speaking learners were all English majors learning English as a foreign language in Shanghai, China. None of the students studied English in an English-speaking country. The native speakers of American English were students at a medium-size public institution in the United States.

\subsection{Materials and Design}

There were two experiments for the present study. Experiment 1 addressed the first research question, that of whether L2 learners follow the constraints of the minimal processing effort of RT when they process reflexive anaphora in VP-ellipsis. I presented 17 experimental sentences (Appendix) of the same form as (1) to the subjects along with 34 filler (distracter) sentences.

Experiment 2 addressed the second research question, that of whether an ensuing referential sentence imposes procedural constraints on the inferential phase of comprehension by L2 learners when they process reflexives in the VP-elliptical construction, thus showing the contextual effects of RT. Experiment 2 used the same experimental sentences as Experiment 1, but the sentences were followed by a referential context favoring the strict interpretation, as in (11), by a non-referential context not favoring the strict interpretation, as in (12), and 51 unambiguous filler items, as in (13). 
172 Relevance and L2 Learners' Interpretation of Reflexive Anaphora in

(11) John defended himself and Bill did too. Bill was a good friend of John.

(12) John defended himself and Bill did too. Bill went to a restaurant afterwards.

(13) John saw Catherine yesterday and Bill did too.

\subsection{Procedure}

Before the experiments, the Chinese-speaking learners of English were asked to complete a language history survey. Information about their age and years of English learning is reported in Table 1.

Table 1. Age and Years of English Learning

\begin{tabular}{|l|c|c|}
\hline & Mean (s.d.) & Range \\
\hline Age $(\mathrm{N}=50)$ & $21.68(1.87)$ & $18-26$ \\
\hline $\begin{array}{l}\text { Years of English } \\
\text { learning }(\mathrm{N}=50)\end{array}$ & $9.5(1.30)$ & $8-13$ \\
\hline
\end{tabular}

After the survey, they were asked to take a simplified version of the TOEFL test. The test consists of 25 questions on English Structure, and 25 questions on Reading Comprehension. The test did not include the listening comprehension questions, because this study was not aimed at testing the subjects' listening comprehension ability. But a basic understanding of English sentence structure and their ability to make inferences were important for this study, because the experiments not only dealt with single sentences, they also involved making inferences based on an ensuing linguistic context. Thus the test included two sections of the TOEFL test, the Structure section (25 points) and the Reading Comprehension 
section ( 25 points). The test began with written instructions and examples. The students were asked to identify and circle one out of the four given choices. The purpose of the test was to measure the students' English proficiency and to group them according to their English proficiency levels. Students of different levels of English proficiency were included in the experiments because the experiments were aimed at finding out how these students would interpret the ambiguous structures in English. Thomas (1993) administered a similar test, which also included 50 test items, each with one point. In her study the mid level had scores between 32 and 40, and the high level had scores between 41 and 50. In this study, the mid level had scores between 31-39, and the high level had scores between 40 and 49. The mid level ended with 39 instead of 40 , because $40,80 \%$ of the total score, appears to be a score that characterizes a high proficiency level. The high level ended with 49, because this was the highest score of the test. The original pool consisted of 41 sophomores and 29 seniors. The subjects were regrouped according to the test results, with the intermediate level having 28 and the advanced level having 22 randomly selected students. The results of the test at each level are reported in Table 2.

Table 2. TOEFL Test Results

\begin{tabular}{|c|c|c|}
\hline & Mean (s.d.) & Range \\
\hline Intermediate & $34.64(2.48)$ & $31-39$ \\
\hline Advanced & $45.09(2.74)$ & $40-49$ \\
\hline
\end{tabular}

Then the experiments began. For Experiment 1, 17 experimental sentences of the same form as (1) and 34 fillers were presented in random order to the participants. Following Frazier \& Clifton (2000), we used a judgment task in which each sentence is followed by two alternative interpretations: 
174 Relevance and L2 Learners' Interpretation of Reflexive Anaphora in

(14) John defended himself and Bill did too.

What does the underlined part of the sentence mean? Bill defended Bill. Bill defended John.

As in Frazier \& Clifton (2000), the participants in my study were asked to check which version matched their initial understanding of the underlined part of the sentence. In other words, the students were instructed to check an answer that first comes to their mind without rethinking or editing. They were instructed NOT to go back and make changes after they had made the choice.

After 2 weeks, Experiment 2 took place. The Chinese students were presented with the same 17 experimental sentences, but the sentences were followed by a referential context favoring the strict interpretation, as in (11), by a non-referential context not favoring the strict interpretation, as in (12), and 51 unambiguous filler items, as in (13). The following is an example of experimental sentences in a referential context.

(15) Jane criticized herself and Jennifer did too. Jennifer did not like Jane.

What does the underlined part of the sentence mean? Jennifer criticized Jennifer. Jennifer criticized Jane.

The students were given the same instruction as they did in Experiment 1. The twenty students of American English (the control group) were given the same experiments, with the same time interval between the two experiments. 


\subsection{Results}

Table 3. Performance on the 17 Experimental Sentences by Chinesespeaking Learners of English and Native Speakers of American English

\begin{tabular}{|c|c|c|c|}
\hline & $\begin{array}{l}\text { C-Group 1 } \\
\text { (intermediate) } \\
(\mathrm{n}=28) \\
\text { M (s.d.) }\end{array}$ & $\begin{array}{c}\text { C-group 2 } \\
\text { (advanced) } \\
(\mathrm{n}=22) \\
\text { M (s.d.) }\end{array}$ & $\begin{array}{c}\text { English group } \\
\text { (native speakers) } \\
(\mathrm{n}=20) \\
\mathrm{M}(\mathrm{s} . \mathrm{d} .)\end{array}$ \\
\hline Sloppy reading & $13.96(1.99)$ & $12.59(2.08)$ & $12.90(2.15)$ \\
\hline Strict reading & $3.04(1.99)$ & $4.41(2.08)$ & $4.10(2.15)$ \\
\hline
\end{tabular}

Table 3 reports the performance on 17 experimental sentences by two Chinese groups and native speakers of American English. The intermediate Chinese Group (C-Group 1) interpreted the reflexive in VP-ellipsis sloppily ( $\mathrm{M}=13.96$ for the sloppy interpretation vs. $\mathrm{M}=3.04$ for the strict interpretation). The advanced Chinese group (C-Group 2) patterned like the intermediate Chinese group in terms of their reading of the reflexive $(\mathrm{M}=12.59$ for the sloppy reading vs. $\mathrm{M}=4.41$ for the strict reading). The Chinese learners of English were comparable with native speakers of English, who also interpreted the reflexive sloppily $(\mathrm{M}=12.90$ for the sloppy reading vs. $\mathrm{M}=4.10$ for the strict reading). The differences of the sloppy interpretation across the two Chinese groups were found to be statistically significant, $F(1,48)=3.76, p<.05$. The differences between the native speakers and the intermediate L2 learners in terms of the sloppy reading were found to be statistically significant, too, $\mathrm{F}$ (1, $46)=3.48, p<.05$. But the differences between the native speakers and the advanced L2 learners in terms of the sloppy reading were found to be statistically non-significant, $F(1,40=2.16, p>.05$. 
Relevance and L2 Learners' Interpretation of Reflexive Anaphora in

Table 4. Performance on the 17 Experimental Sentences in a Referential and Non-referential Context by Chinese-speaking Learners of English and Native Speakers of American English

\begin{tabular}{|l|c|c|c|c|}
\hline \multirow{2}{*}{} & \multicolumn{2}{|c|}{ Referential } & \multicolumn{2}{c|}{ Non-Referential } \\
\cline { 2 - 5 } & Sloppy & Strict & Sloppy & Strict \\
\cline { 2 - 5 } & $\mathrm{M}$ (s.d.) & $\mathrm{M}$ (s.d.) & $\mathrm{M}$ (s.d.) & $\mathrm{M}$ (s.d.) \\
\hline $\begin{array}{l}\text { C-Group 1 } \\
(\mathrm{N}=28) \\
(\text { Intermediate) }\end{array}$ & $5.96(2.03)$ & $11.04(2.03)$ & $8.93(1.98)$ & $8.07(1.98)$ \\
\hline $\begin{array}{l}\text { C-Group 2 } \\
(\mathrm{N}=22) \\
(\text { Advanced) }\end{array}$ & $4.91(1.63)$ & $12.09(1.63)$ & $9.49(1.40)$ & $7.51(1.40)$ \\
\hline $\begin{array}{l}\text { English Group } \\
(\mathrm{N}=20)\end{array}$ & $3.05(1.32)$ & $13.95(1.32)$ & $9.45(1.05)$ & $7.55(1.05)$ \\
\hline
\end{tabular}

Table 4 reports the performance on the 17 experimental sentences in a referential and non-referential context by Chinesespeaking learners of English and native speakers of American English. The intermediate Chinese Group (C-Group 1) showed a preference for the strict interpretation in a referential context $(M=11.04$ for the relative clause interpretation vs. $M=5.96$ for the sloppy interpretation). In comparison, they did not show a preference for the strict interpretation in a non-referential context $(\mathrm{M}=8.07$ for the strict interpretation vs. $\mathrm{M}=8.93$ for the sloppy interpretation). The advanced Chinese group (C-Group 2) patterned like the intermediate Chinese group with respect to their preferences for the strict interpretation in a referential context $(\mathrm{M}=12.09$ for the strict interpretation vs. $M=4.91$ for the sloppy interpretation). On the other hand, there were no such preferences in a non-referential context $(M=7.59$ for the strict interpretation vs. $M=9.49$ for the sloppy interpretation). The Chinese-speaking learners of English were comparable with native speakers of English, who also showed 
a strong preference for the strict interpretation in a referential context $(M=13.95$ for the strict interpretation vs. $M=3.05$ for the sloppy interpretation). However, there were no such preferences in a non-referential context ( $\mathrm{M}=7.55$ for the strict interpretation vs. $M=9.45$ for the sloppy interpretation). The differences between the native speakers and the intermediate and advanced Chinese learners in terms of the strict reading in a referential context were found to be statistically significant, $F(1,67)=4.12, p<.05$. And the differences across the two Chinese groups with respect to the strict interpretation in a referential context were also found to be statistically significant, $\mathrm{F}(1,48)=3.26, \mathrm{p}<.05$.

An examination of the individual results concerning the strict reading indicates the advanced L2 learners did so to a much greater extent than the intermediate learners (Table 5).

Table 5. Individual Data on the 17 VP-elliptical Sentences with the Strict Reading by the Intermediate and Advanced Chinese-speaking Learners of English

\begin{tabular}{|c|c|c|}
\hline $\begin{array}{c}\text { Percentages of } \\
\text { The strict Interpretation }\end{array}$ & $\begin{array}{c}\mathrm{C} 1 \\
(\text { Intermediate }) \\
(\mathrm{n}=28)\end{array}$ & $\begin{array}{c}\mathrm{C} 2 \\
\text { (Advanced) } \\
(\mathrm{n}=22)\end{array}$ \\
\hline $47.1 \%$ & 0 & 1 \\
\hline $41.2 \%$ & 1 & 3 \\
\hline $35.3 \%$ & 3 & 3 \\
\hline $29.4 \%$ & 3 & 4 \\
\hline $23.5 \%$ & 4 & 4 \\
\hline $17.6 \%$ & 5 & 2 \\
\hline $11.8 \%$ & 5 & 1 \\
\hline $5.9 \%$ & 4 & 1 \\
\hline $0.0 \%$ & 3 & \\
\hline & & 3 \\
\hline
\end{tabular}




\subsection{Discussion}

The experiments investigated (a) whether L2 learners follow the constraint of the minimal processing effort of RT in processing reflexive anaphora in VP-ellipsis, and (b) whether an ensuing referential sentence imposes procedural constraints on the inferential phase of comprehension by L2 learners when they process reflexives in the VP-elliptical sentences, thus showing the contextual effects of RT. The results appear to provide positive answers to both questions.

Experiment 1 showed that the minimal processing effort of RT constrained the adult L2 learners' (and the native speakers') interpretation of reflexives in the VP-elliptical construction. The intermediate and advanced Chinese-speaking learners of English chose the most accessible 'sloppy' reading as the interpretation of the reflexive in the VP-elliptical structure. The sloppy (i.e., the lower subject) interpretation involves the least effort in computing cognitive effects mainly for two reasons. First, copying the antecedent VP into the elided VP was immediately available in the linguistic information of the sentence. Second, seeking the lower subject to be the antecedent for the reflexive was easier than seeking, for example, the higher subject as the antecedent for the reflexive, not only because the distance between the reflexive and the lower antecedent is shorter than the distance between the reflexive and the higher subject, but also because the binding relationship between the reflexive and the lower subject is within a single bounding node ${ }^{4}$. In contrast, the strict (i.e., the higher subject) reading is costly on the grounds that (i) the pronoun reading, which involves a change to the pronoun from the reflexive, is not immediately available in the

${ }^{4}$ Bounding nodes in English include IP and NP. For example, the sentence "John defended himself, and Bill did too" has two bounding nodes: [IP John defended himself [conj and [iP Bill did too]]]. For lucid discussion of bounding nodes, see Cook \& Newson (1996) and Haegeman (1994). 
linguistic information of the sentence, (ii) the distance between the reflexive and its higher antecedent is greater than the distance between the reflexive and its lower antecedent, and (iii) the binding relationship of the reflexive in the elided VP with its higher subject is not within a single bounding node: it crosses one bounding node. Thus, constrained by the least processing effort of RT, the L2 learners plowed ahead with the most accessible 'sloppy' interpretation, as evidenced by the high percentages of the 'sloppy' interpretation $(82.1 \%$ for the intermediate learners and $74.1 \%$ for the advanced learners).

Experiment 2 showed that the contextual effects of RT constrained the L2 learners' processing of reflexives in the VP-elliptical construction in a referential context. The ensuing referential information constrained the inferred conclusion about encoding the reflexive in VP-ellipsis. Hence the L2 learners' strict reading of the reflexive in the VP-elliptical structure. In constraining the inferential processing of ambiguous sentences this way, the procedural information encoded by ensuing referential sentences had the effect of reducing the overall computational effort required and of guiding the L2 learners (as well as the native speakers) towards the intended contextual effects.

The ensuing non-referential sentences in Experiment 2 did not constrain the inferential processing of the ambiguous sentences. Neither the L2 learners nor the native speakers showed a clear tendency toward interpreting the reflexive strictly. This result is consistent with the assumptions of RT. RT assumes that the noninferential information presented in the context following the experimental sentences carries the presumption of relevance. The participants would expect the information presented to be worth their effort. In an attempt to establish the relevance of the information presented, they spent extra processing effort for no extra contextual effects: they found the ensuing information to be nonreferential to the foregoing experimental sentence. Thus, the 
following irrelevant information distracted the participants' ability to process the experimental sentences, leading to their lower performance in the experiment (For discussion of children's lower performance in such a context, see Chien \& Wexler 1990, FosterCohen 1994, Grimshaw an Rosen 1990, McKee 1992, among others). This explains why the participants performed more poorly in encoding the reflexive as a strict interpretation in the experimental sentences that are followed by a non-referential context (12) than they did when the ensuing information was relevant to the strict interpretation (11). It also explains why they performed more poorly in interpreting the reflexive sloppily than they did in Experiment 1, where their ability to process the experimental sentences was not distracted by the irrelevant information.

As Table 3 shows, the intermediate Chinese L2 learners had a higher percentage of sloppy reading than the advanced learners, but they had a lower percentage of strict reading than their advanced peers. This calls for an explanation. Sperber $(1994,2000)$ suggests that all communicators follow a path of least effort in computing cognitive effects, but there are varying degrees of expectations of relevance in the course of comprehension. He discusses three increasingly sophisticated strategies used for comprehension. The simplest strategy is that of what he calls "naïve optimism" (Sperber 1994:189). An addressee using this strategy looks for an interpretation that appears to be relevant enough. If the addressee finds one, s/he assumes that it was the intended interpretation and attributes it to the addresser's meaning. A more complex strategy is that of what he calls "cautious optimism" (ibid, 191). In addition to taking the first interpretation as relevant enough and attributing it to the addresser's meaning, an addressee using this strategy also considers what interpretation the speaker might have thought would be relevant enough (Wilson 2000, italics hers). A third strategy is that of "sophisticated understanding" (ibid, 194). An addressee using this 
strategy considers what interpretation the speaker might have thought he would think was relevant enough (Wilson 2000, italics hers). In other words, the person using this strategy can go beyond cases in which nothing more than the appearance of relevance is achieved and perform at a more abstract and elaborate level. It appears that the intermediate Chinese-speaking learners of English used the strategies of naïve optimism and cautious optimism. Copying the antecedent VP into the elided VP and having the local antecedent for the reflexive in the elided VP, they interpreted the reflexive sloppily using the strategy of naïve optimism. But they sometimes ventured into strict reading using the strategy of cautious optimism: one student did so $41.2 \%$, three $35.3 \%$, three $29.4 \%$, four $23.5 \%$, five $17.6 \%$, five $11.8 \%$, four $5.9 \%$ and three $0.0 \%$ (Table 5 ). On the other hand, the advanced Chinese-speaking learners of English appear to have used all three strategies. Like their intermediate peers, they interpreted the reflexive sloppily using the strategy of naïve optimism: the sloppy interpretation was available in the linguistic environment of the sentence and did not require gratuitous processing effort. But they were more adept at using the strategies of cautious optimism and sophisticated understanding, which resulted in a higher percentage of strict reading than their intermediate peers: one student did so $47.1 \%$, three $41.2 \%$, three $35.3 \%$, four $29.4 \%$, four $23.5 \%$, three $17.6 \%$, two $11.8 \%$, one $5.9 \%$ and one $0.0 \%$ (Table 5 ).

The Chinese L2 learners used the strategy of naïve optimism, but the intermediate learners did so to a greater extent than their advanced peers. This explains why the intermediate learners had a higher percentage of the sloppy reading $(82.1 \%)$ than the advanced learners $(74.1 \%)$. The strategies apart, there appear to be similar cognitive processes at work. The L2 learners' dominant sloppy interpretation indicates that the least computational effort of RT constrained their interpretation of the reflexive in the elided VP.

The result of Experiment 2 shows that in terms of the strict 
182 Relevance and L2 Learners' Interpretation of Reflexive Anaphora in

reading, there were significant differences between the learners and native speakers. Such differences were also found between the intermediate learners and the native speakers in term of the sloppy reading in Experiment 1, but not between the advanced learners and the native speakers. Our findings concerning the differences between the L2 learners and native speakers converge with those of Fernández (1999) and Hahne (2001), who also found out that native speakers of English and L2 learners differ in language processing. Our result concerning the sloppy reading between the advanced learners and native speakers supports Pérez-Leroux \& Li (1998), who also reported that there were no statistically significant differences between advanced learners and native speakers in terms of their command of complex NP islands. But why the advanced learners and native speakers differ significantly with respect to the strict reading (Experiment 2), but not with the sloppy reading (Experiment 1) is something we hope we can address in our future research. $^{5}$

Processing the single sentences in Experiment 1 appears to be syntactic parsing in nature while processing the sentences in a referential context in Experiment 2 appears to be pragmatic parsing in nature. The way syntax and pragmatics relate is a central issue in the study of language, including language processing. Distinguishing between grammar and pragmatics, Chomsky (1980:59, 224-225) views 'grammatical competence' as the computational aspects of language, that constitute knowledge of form and meaning, and 'pragmatic competence' as knowledge of the conditions for

\footnotetext{
5 One possible explanation is that although constrained by the contextual effects of RT, our advanced learners still lagged behind the native speakers in terms of their inferential ability (i.e., the ability to obtain the strict reading based on ensuing referential cues), leading to their lower performance than the native speakers in Experiment 2. On the other hand, since such inferential ability was not a significant factor in terms of the sloppy reading in Experiment 1, there were no significant differences between our advanced learners and the native speakers.
} 
appropriate use, of how to use grammatical and conceptual resources to achieve certain ends or purposes. It can be inferred from the logic of Chomsky's position on pragmatic competence that there must be some sort of pragmatic performance mechanisms that put this pragmatic knowledge system to use (Carston 2000). On the other hand, Sperber \& Wislon (1986/19995: 202-217) view the boundary between grammar and pragmatics as 'a natural linkage between linguistic form and pragmatic interpretation'. Their idea is that the way linguistic information is organized syntactically affects its processing. Linguistic devices such as connectives act as a processing constraint on the inferential relations between the propositional content of a linguistic expression and the context to arrive at the intended interpretation. For instance, 'after all' in (10) signals that the proposition it introduces can be used as a premise in an argument supporting the preceding assertion ('He is brave'). The present study indicates that the referential sentential information also imposes constraints on L2 learners' inferential processing, showing the contextual effects of RT.

The coded processing appears to be governed by the least processing effort of RT. In Experiment 1, the Chinese-speaking learners of English patterned like NSs in their preferences for the sloppy reading that involves the expenditure of minimal processing effort. The referential processing appears to be constrained by the contextual effects of RT. In Experiment 2, the L2 learners and native speakers interpreted the reflexive strictly using the pragmatic information encoded by the following referential sentences. Thus, the L2 learners' (and the native speakers') language parsing mechanisms (or central processes) appear to be relevance-constrained. ${ }^{6}$ As Neil

6 We are not claiming that relevance theory is the best tool for language comprehension and understanding. What we are saying is that the principle of relevance that has not been fully investigated in L2 sentence processing appears to provide a novel perspective on the way our participants interpret reflexive anaphora in VP-ellipsis. 
184 Relevance and L2 Learners' Interpretation of Reflexive Anaphora in

Smith (2002:9) well put it, by reference to 'relevance' we arrive at the meaning intended as well as the linguistic meaning.

\section{An Exploration of the Relationship between Relevance Theory and Typological Universals}

Relevance Theory is a cognitive theory of communication. It assumes that human cognition is relevance-based: we pay attention to information that seems relevant to us (Wilson 1994). Similarly, the goal of typological studies can be said to have two facets: (1) achieving cognition, and (2) representing cognition (Seiler 1995, 2001). Cognition is achieved in the individual speech act when the speaker uses the forms of his or her language creatively. This means that the spoken or written word is considered as the output of mental operations. In other words, language is the primary means of thinking and of achieving cognitive insight, and it is at the same time the means of representing such insight. Thus, in its cognitive function, language is minimally dependent on the grammatical pattern, because the definition of our experience stands in complementary relation to metalinguistic operations - the cognitive level not only admits but directly requires recoding interpretation (Jakobson 1959/1971, cited in Seiler 1995). From this perspective, linguistic comparison does not give access to, nor is it based on, a universal logic. What is truly universal is not the intermediate states we can observe in a series of languages, giving rise to 'types' of expression for possession or object marking, but the cognitive maps behind such developments (Raible 2001, italics his) and the dependence of cognition on 'articulated sounds' (Shibatani \& Byron 1995).

Section 4 shows that context plays a crucial role in Relevance Theory. Context refers to not simply the preceding linguistic text or the environment in which the utterance takes place, but a set of 
assumptions brought to bear in arriving at the intended interpretation (Wilson 1994). Researchers of language typology hold a similar view. Seiler (1995), for example, states that context is crucial for speakers to use the forms of their language, including translation. In fact, he cites Sperber \& Wilson (1986) and notes that their notion of 'relevance to the situation' is fundamental for metalinguistic operations in typological research (see Raible (2001) for similar quotes and discussion of Sperber \& Wilson 1986/1995). He says that the richer the verbal context, the smaller the loss of information in translation, and that the terser the verbal context and the more reliance on 'relevance to the situation', the more creative transposition is required from the translator. Thus, in trying to give a full account of the functional load and the systematic interplay of the linguistic devices, not just the representational part of the language functions has to be considered, but the textual and the situational context (Premper 2001). This means that 'pragmatic' and 'textual' issues add to the purely 'syntactic' ones, providing us with the means to linguistically express 'Relevance' (Raible 2001, quotes his).

Relevance Theory posits constraints in terms of the principle of relevance. In fact, constraints are also an important consideration for language universals. Language universals reflect the belief that there exist linguistic features beyond the essential definitional properties of language. Greenberg (1978) discovered that a more systematic sampling of a substantial number of languages reveals not only the range of variation but constraints on that variation. Those constraints demonstrate that languages do not vary infinitely, and the constraints represent linguistic universals. Hence, the primary focus on universals in the typological tradition has been on their crosslinguistic validity, and on universals that restrict possible language variation (For discussion of typological constraints, see Croft 2001).

Both Relevance Theory and typological universals believe that constraints may be innate. Sperber \& Wilson assume that the 
principle of relevance is innate since it governs not only linguistic behavior, but all of human information processing (Foster-Cohen 1994). Typological universals call for explanation in terms of more general cognitive, processing, perceptual or other abilities. These abilities may also be innate, but they extend beyond language per se. In fact, the codifying and decodifying strategies of linguistic messages hinge upon the influence of biological conditioning (Ramat 1995). As Croft (2003) put it, for typological approaches, the foundations of linguistic explanation are ultimately biological.

As discussed in Section 4, economy, the principle that the expressions should be minimized where possible, is an important consideration for Relevance Theory. This is also true of typological universals. In typological research, structural coding restricts the possibility of zero vs. overt coding of the value of conceptual category of grammatical expression in languages. The underlying concept of structural coding is a typological generalization that characterizes the asymmetric distribution of zero vs. overt coding across languages. This asymmetry underling structural coding is described as economic motivation or more simply, economy. Economy is most straightforwardly a processing consideration. Processing efficiency for both speaker and hearer is increased by shortening the most common forms (structural coding) and simplifying the less-used forms. Economy reflects processing efficiency, by minimizing the number of distinct linguistic forms that must be acquired and retained in use. Thus, the best coding is that which is economically most motivated (DuBois 1985, Sgall 1995).

\section{Summary}

This study provides a relevance-theoretic account of how L2 learners process reflexive anaphora in VP-ellipsis and explores the 
relationship between relevance theory and language typology. It addresses perhaps the most basic question in language processing, that of why the processor initially favors one analysis over another (Garrot \& Pickering 1999). The two experiments reported in this study presented evidence that the principle of relevance constrained the adult L2 learners' processing of the ambiguous sentences in English. In Experiment 1, constrained by the minimal processing effort of RT, both the intermediate and advanced Chinese-speaking learners of English interpreted the reflexive sloppily. In Experiment 2 , they interpreted the reflexive strictly, using the procedural information encoded by the ensuing referential sentences. Such information had the effect of reducing the overall computational effort required and of guiding the L2 learners towards the intended contextual effects. The article also discusses the relationship between relevance theory and language typology in terms of cognition, context, constraints and economy.

\section{References}

Baltin M. \& C. Collins. (eds.). The Handbook of Contemporary Syntactic Theory. Oxford: Blackwell.

Barss, A. 1986. Chains and Anaphoric Dependence. Doctoral Dissertation, Cambridge, MA: MIT. . 1988. Paths, Connectivity, and Featureless Empty Categories. In

A. Sardinaletti, B. Cinque, \& G. Giusti (eds.), Constituent Structure 934. Dordrecht: Foris.

. 1993. Sentence Processing and the Grammar of Anaphora. In G.

Altmann \& R. Shillcock (eds.), Cognitive Models of Speech Processing 401-451. Hilldale, NJ: Lawrence Erlbaum.

. 1994. Derivations and Reconstruction. Studies in the Linguistic

Sciences 24, 19-38.

. 2001. Syntactic Reconstruction Effects. In M. Baltin \& C. 
188 Relevance and L2 Learners' Interpretation of Reflexive Anaphora in

Collins (eds.), The Handbook of Contemporary Syntactic Theory 670696. Oxford: Blackwell.

Bennett, S. 1994. Interpretation of English Reflexives by Adolescent Speakers of Serbo-Croatian. Second Language Research 10, 125-156.

Bennett, S. \& L. Progovac. 1998. Morphological Status of Reflexives in

Second Language Acquisition. In S. Flynn, G. Martohardjono, \& W.

O'Neil (eds.), The Generative Study of Second Language Acquisition 187-214. Mahwah, NJ: Lawrence Erlbaum.

Blakemore, D. 1987. Semantic Constraints on Relevance. Oxford: Blackwell.

- 1988. So as a Constraint on Relevance. In R. Kempson (ed.), Mental Representation: The Interface between Language and Reality 183-195. Cambridge: Cambridge University Press. . 1992. Understanding Utterances. Oxford: Blackwell. - 1997. Restatement and Exemplification: A Relevance Theory Reassessment of Elaboration. Pragmatics and Cognition 5, 119. . 2000. Indicators and Procedures: Nevertheless and But. Journal of Linguistics 36, 463-486. . 2002. Relevance and Linguistic Meaning: The Semantics and Pragmatics of Discourse Markers. Cambridge: Cambridge University Press.

Cameron, R. \& J. Williams. 1997. Sentence to Ten Cents: A Case Study of Relevance and Communicative Success in Nonnative-native Speaker Interactions in a Medical Setting. Applied Linguistics 18, 415-445.

Carroll, S. 2001. Input and Evidence: The Raw Material of Second Language Acquisition. Amsterdam: John Benjamins.

Carston, R. 2000. The Relationship between Generative Grammar and (Relevance-theoretic) Pragmatics. Language and Communication 20, 87-103.

Chien, Y. \& K. Wexler. 1990. Children's Knowledge of Locality Conditions in Binding as Evidence for the Modularity of Syntax and Pragmatics. Language Acquisition 1, 225-295. 
Chomsky, N. 1980. Rules and Representations. Oxford: Blackwell.

. 1981. Lectures on Government and Binding. Dordrecht: Foris. . 1986. Knowledge of Language. NY: Praeger.

1993. A Minimalist Program for Linguistic Theory. In K.

Hale \& J. Kester (eds.), The View from Building 20: Essays in Honor of Sylvain Bromberger 1-50. Cambridge, MA: MIT Press. . 1995. The Minimalist Program. Cambridge, MA: MIT Press.

Cinque, G. 1982. Constructions with Left-peripheral Phrases, "Connectedness," Move a and ECP. Venice: University of Venice.

Cole, P. \& L. Sung. 1994. Head Movement and Long-distance Reflexives. Linguistic Inquiry 25, 355-406.

Cook, V. \& M. Newson. 1996. Chomsky's Universal Grammar: An Introduction. Oxford: Blackwell.

Croft, W. 2001. Radical Construction Grammar: Syntactic Theory in Typological Perspective. Oxford: Oxford University Press. . 2003. Typology and Universals. Cambridge: Cambridge University Press.

Culicover, P. 1997. Principles and Parameters: An Introduction to Syntactic Theory. Oxford: Oxford University Press.

Dalrymple, M., S. Shieber, \& F. Pereira. 1991. Ellipsis and Higher-order Unification. Linguistics and Philosophy 14, 399-452.

DuBois, J. 1985. Competing Motivation. In J. Haiman (ed.), Iconicity in Syntax 343-366. Amsterdam: John Benjamins.

Fiengo, R. \& R. May. 1994. Indices and Identity. Cambridge, MA: The MIT Press.

Fodor, J. 1983. The Modularity of $<$ ind. Cambridge, MA: MIT Press.

Foster-Cohen, S. 1994. Exploring the Boundary between Syntax and Pragmatics: Relevance and the Binding of Pronouns. Journal of Child Language 21, 237-255.

. 1999. SLA and First Language Acquisition. Annual Review of Applied Linguistics 19, 3-21.

. 2000. Review Article of D. Sperber \& D. Wilson (1995):

Relevance: Communication and Cognition. Second Language Research 
190 Relevance and L2 Learners' Interpretation of Reflexive Anaphora in

$16,77-92$.

Frazier, L. \& C. Clifton. 2000. On Bound Variables Interpretations: The

LF-only Hypothesis. Journal of Psycholinguistic Research 29, 125-139.

Frazier, L. \& J. De Villiers. 1990. Introduction. In L. Frazier \& J. De

Villiers (eds.). Language Processing and Language Acquisition 24-45.

Dordrecht: Kluwer.

Garrod, S. \& M. Pickering. 1999. Issues in Language Processing. In A.

Garrod \& M. Pickering (eds.) Language Processing 134-151. UK:

Psychology Press.

Gibson, E. \& N. Pearlmutter. 2000. Distinguishing Serial and Parallel

Parsing. Journal of Psycholinguistic Research 29, 231-240

Greeberg, J. 1978. Typology and Cross-linguistic Generalizations. In J.

Greenberg, et al. (eds.), Universals of Human Language 33-59.

Stanford, CA: Stanford University Press.

Grice, H. 1975. Logic and Conversation. In P. Cole \& J. Morgan (eds.),

Syntax and Semantics 3: Speech Acts. New York: Academic Press.

Grimshaw, J. \& S. Rosen. 1999. Knowledge and Obedience: The

Developmental Status of the Binding Theory. Linguistic Inquiry 21, 187-222.

Haegeman, L. 1994. Introduction to Government \& Binding Theory.

Oxford: Blackwell.

Hahne, A. 2001. What's Different in Second-language Processing?

Evidence from Event-related Brain Potentials. Journal of

Psycholinguistic Research 30, 251-266.

Hestvik, A. 1995. Reflexives and Ellipsis. Natural Language Semantics 3, 211-237.

Heycock, C. 1995. Asymmetries in Reconstruction. Linguistic Inquiry 26, 547-570.

Huang, C-T. J. 1993. Reconstruction and the Structure of VP: Some Theoretical Consequences. Linguistic Inquiry 24, 103-138.

Jakobson, R. 1959/1971. On Linguistics Aspects of Translation. In Selected Writings 2, 260-266. The Hague: Mouton.

Johnson, K. 2001. What VP Ellipsis can Do, and What it can't, but not 
Why. In M. Baltin \& C. Collins (eds.), The Handbook of Contemporary Syntactic Theory 439-480. Oxford: Blackwell.

Kitagawa, Y. 1991. Copying Identity. Natural Language and Linguistic Theory 9, 497-536.

Koopman, H. \& D. Sportiche. 1991. The Position of Subjects. Lingua 85, 211-258.

Lasnik, H. 1999. Minimalist Analysis. Oxford: Blackwell.

2001. Derivation and Representation in Modern Transformational Syntax. In M. Baltin \& C. Collins (eds.), The Handbook of Contemporary Syntactic Theory 62-88. Oxford: Blackwell. MacLaughlin, D. 1998. The Acquisition of Morphosyntax of English Reflexives. In M. Beck (ed.), Morphology and its Interfaces in Second Language Knowledge 195-226. Amsterdam: John Benjamins.

McKee, C. 1992. A Comparision of Pronouns and Anaphors in Italian and English Acquisition. Language Acquisition 2, 21-54.

Newmeyer, F. 1998. Language Form and Language Function. Cambridge, MA: MIT Press.

Nicolle, S. 1998. A Relevance Theory Perspective on Grammaticalization. Cognitive Linguistics 9, 1-35.

Pennington, M. 2002. Grammar and Communication: New Directions in Theory and Practice. In E. Hinkel \& S. Fotos (eds.), New Perspectives on Grammar Teaching in Second Language Classrooms 77-98. Mahwah, NJ: Lawrence Erlbaum.

Pérex-Leroux, A. \& X. Li. 1998. Selectivity in the Acquisition of Complex NP Islands. In E. Klein \& G. Martohardjono (eds.), The Development of Second Language Grammars: A Generative Approach 147-168. Amsterdam: John Benjamins.

Premper, W. 2001. Universals of the Linguistic Representation of Situations ('Participation'). In M. Haspelmath, et al. (eds.), Language Typology and Language Universals: An International Handbook 477495. Berlin: Walter de Gruyter.

Progovac, L. 1992. Relativized SUBJECT: Long-distance Reflexives without Movement. Linguistic Inquiry 23, 671-680. 
192 Relevance and L2 Learners' Interpretation of Reflexive Anaphora in

. 1993. Long-distance Reflexives: Movement-to-Infl versus Relativized SUBJECT. Linguistic Inquiry 24, 755-772.

Raible, W. 2001. Language Universals and Language Typology. In M. Haspelmath, et al. (eds.), Language Typology and Language Universals: An International Handbook 1-24. Berlin: Walter de Gruyter.

Ramat, P. 1995. Typological Comparison. In M. Shibatani \& T. Byron. (eds.), Approaches to Language Typology 27-48. Oxford: Clarendon.

Reuland, E. \& M. Everaert. 2001. Deconstructing Binding. In M. Baltin \& C. Collins (eds.), The Handbook of Contemporary Syntactic Theory 670-696. Oxford: Blackwell.

Roberts, I. 1997. Comparative Syntax. London: Arnold.

Safir, K. 2004. The Syntax of Anaphora. Oxford: Oxford University Press.

Seiler, H. 1995. Universals and Typology in UNITYP. In M. Shibatani \& T. Byron (eds.), Approaches to Language Typology 273-326. Oxford: Clarendon. . 2001. The Cologne UNITYP Project. In M. Hasperlmath, et al. (eds.), Language Typology and Language Universals: An International Handbook 323-344. Berlin: Walter de Gruyter.

Sgall, P. 1995. Prague School Typology. In M. Shibatani \& T. Byron (eds.). Approaches to Language Typology 49-84. Oxford: Clarendon.

Shibatani, M. \& T. Byron. 1995. Approaches to Language Typology: A Conspectus. In M. Shabatani \& T. Byron (eds.), Approaches to Language Typology 1-26. Oxford: Clarendon.

Shieber, S., F. Pereira. \& M. Dalrymple. 1996. Interaction of Scope and Ellipsis. Linguistics and Philosophy 19, 527-52.

Smith, N. 2002. Language, Bananas and Bonobos. Oxford: Blackwell.

Sperber, D. 1994. Understanding Verbal Understanding. In J. Khalfa (ed.), What is Intelligence 179-198. Cambridge: Cambridge University Press. . 2000. Metarepresentations in an Evolutionary Perspective. In

D. Sperbe (ed.), Metarepresentations: A Multidisciplinary Perspective 117-137. Oxford: Oxford University Press.

Sperber, D. \& D. Wilson. 1986/1995. Relevance: Communication and 
Cognition. Oxford: Blackwell.

Takano, Y. 1995. Predicate Fronting and Internal Subjects. Linguistic Inquiry 26, 327-340.

Thomas, M. 1995. Acquisition of the Japanese Reflexive Zibun and

Movement of Anaphors in Logical Form. Second Language Research 11, 206-234.

Wilson, D. 1992. Reply to Chametzky. Journal of Pragmatics 17, 73-77. . 1994. Relevance and Understanding. In G. Brown, et al. (eds.), Language and Understanding 35-58. Oxford: Oxford University Press. . 2000. Metarepresentation in Linguistic Communication. In D.

Sperber (ed.), Metarepresentations: A Multidisciplinary Perspective 411-448. Oxford: Oxford University Press.

Wilson, D. \& D. Sperber. 1991. Inference and Implicature. In S. Davis (ed.), Pragmatics: A Reader 377-393. Oxford: Oxford University Press. . 1993. Linguistic Form and Relevance. Lingua

90, 1-25.

Ying, H. 1999. Access to UG and Language Transfer: A Study of L2 Learners' Interpretation of Reconstruction in Chinese. Second Language Research 15, 41-72.

. 2000. Interpretation of Reflexive Binding and the Internal Subject Hypothesis by Chinese-Speaking Learners of English: A Timed Sentence Judgment Task. Paper presented at the Bi-Annual Meeting of Generative Approaches to Second Language Acquisition (GASLA). MA: MIT.

. 2003. Investigating Reconstruction in a Second Language. Muenchen: Lincom Europa Academic Publishers. . 2004. Relevance Mapping: A Study of L2 learners' Processing of Syntactically Ambiguous Sentences in English. Second Language Research 20, 232-255.

Yip, V. \& G. Tang. 1998. Acquisition of English Reflexive Binding by Cantonese Learners: Testing the Positive Transfer Hypothesis. In M. Beck (ed.), Morphology and its Interfaces in Second Language Knowledge 195-226. Amsterdam: John Benjamins. 
194 Relevance and L2 Learners' Interpretation of Reflexive Anaphora in

Yus Ramos, F. 1998. A Decade of Relevance Theory. Journal of Pragmatics 30, 305-345.

\section{Appendix}

17 experimental sentences with reflexive anaphora in VP-ellipsis

1. John defended himself and Bill did too.

2. John believes himself to be heroic and Max does too.

3. Scott voted for himself and Jeff did too.

4. Richard painted himself and James did too.

5. Fred talked about himself, and Robert did too.

6. Jane criticized herself and Jennifer did too.

7. Mary blamed herself and Heather did too

8. Beth likes herself and Catherine does too.

9. Max hit himself and Oscar did too.

10. John admired himself and Bill did too.

11. John introduced himself to the public and Bill did too.

12. John laughed at himself and Bill did too.

13. Jane painted herself and Mary did too.

14. Jennifer wrote herself a memo and Catherine did too.

15. John revealed himself to the public and Bill did too.

16. Nancy loves herself and Wendy does too.

17. Tom hates himself and Jeff does too.

(Based on Fiengo \& May 1994, Hestvik, 1995) 